\title{
Completely steroid-free immunosuppression in liver transplantation: a randomized study.
}

\author{
Carlo B. Ramirez, MD \\ Department of Surgery, Thomas Jefferson University \\ Cataldo Doria, MD, PhD \\ Jefferson Medical College - Thomas Jefferson University Hospital \\ Adam M. Frank, MD \\ Thomas Jefferson University \\ Stephen T. Armenti \\ New York University School of Medicine \\ Ignazio R. Marino, MD \\ Jefferson Medical College and Thomas Jefferson University Hospital, Philadelphia \\ Follow this and additional works at: https://jdc.jefferson.edu/surgeryfp \\ Part of the Surgery Commons \\ Let us know how access to this document benefits you
}

\section{Recommended Citation}

Ramirez, MD, Carlo B.; Doria, MD, PhD, Cataldo; Frank, MD, Adam M.; Armenti, Stephen T.; and Marino, MD, Ignazio R., "Completely steroid-free immunosuppression in liver transplantation: a randomized study." (2013). Department of Surgery Faculty Papers. Paper 123.

https://jdc.jefferson.edu/surgeryfp/123

This Article is brought to you for free and open access by the Jefferson Digital Commons. The Jefferson Digital Commons is a service of Thomas Jefferson University's Center for Teaching and Learning (CTL). The Commons is a showcase for Jefferson books and journals, peer-reviewed scholarly publications, unique historical collections from the University archives, and teaching tools. The Jefferson Digital Commons allows researchers and interested readers anywhere in the world to learn about and keep up to date with Jefferson scholarship. This article has been accepted for inclusion in Department of Surgery Faculty Papers by an authorized administrator of the Jefferson Digital Commons. For more information, please contact: JeffersonDigitalCommons@jefferson.edu. 


\author{
As submitted to: \\ Clinical Transplantation \\ And later published as: \\ Completely Steroid Free Immunosuppression in Liver \\ Transplantation: A Randomized Study \\ Volume 27, Issue 3, May 2013, pp. 463-71 \\ DOI: $10.1111 / \operatorname{ctr} .12119$
}

\footnotetext{
Carlo B. Ramirez, MD ${ }^{\mathrm{a} 1}$, Cataldo Doria, MD, PhD ${ }^{\mathrm{a} 2,}$ Adam M. Frank, $\mathrm{MD}^{\mathrm{a} 3}$, Stephen

T. Armenti, BS ${ }^{\text {b4 }}$, Ignazio R. Marino, $\mathrm{MD}^{\mathrm{a} 5}$
}
${ }^{\mathrm{a}}$ Division of Transplantation, Department of Surgery, Thomas Jefferson University, Philadelphia, PA
${ }^{b}$ NYU School of Medicine, New York University, New York, NY

Funding sources- Novartis Corporation

Trials Registry: Clinical Trials.gov; ID: NCT00296244

Key words: liver transplantation, corticosteroids, calcineurin inhibitors, enteric-coated mycophenolic acid, acute rejection, hepatitis $\mathrm{C}$ recurrence

Word Count: Abstract-237 words; Manuscript- 2937 words

Tables \& Figures: 3 Tables and 2 Figures

Corresponding Author:

Carlo B. Ramirez, MD, FACS

Jefferson Medical College/ 
Thomas Jefferson University Hospital

605 College Building, 1025 Walnut St.

Philadelphia, PA 19107

Tel.: (215) 955-5909

Fax: (215) 923-1420

E-mail: carlo.ramirez@jefferson.edu

\section{FOOTNOTES TO THE TITLE:}

\section{Authors' Contributions}

${ }^{1}$ Principal author- involved in all aspects of the research project (research design, performance of the research, data collection, data analysis, writing of the manuscript).

${ }^{2}$ Participated in research design, performance of the research, and writing of the manuscript.

${ }^{3}$ Participated in performance of the research, data analysis, and writing of the manuscript.

${ }^{4}$ Provided expertise in statistical analysis and writing the paper.

${ }^{5}$ Participated in research design, performance of the research, and writing of the manuscript.

\section{Abbreviations}

ACR Acute cellular rejection

AST Aspartate aminotransferase

ALT alanine aminotransferase

CNI Calcineurin inhibitors

CS Corticosteroids

CMV Cytomegalovirus

DM Diabetes mellitus

EC-MPS Enteric-coated mycophenolate sodium

$\mathrm{HCV}$ Hepatitis $\mathrm{C}$ virus

INR International Normalized Ratio 
I-R Ischemia-reperfusion injury

MAP Mean arterial pressure

MMF Mycophenolate mofetil

NGT Naso-gastric tube

NODM New onset- diabetes mellitus

POD Post-operative day

OLT Orthotopic liver transplantation

\section{ABSTRACT}

Background. Corticosteroids (CS) have always been part of the standard post-transplant immunosuppression to prevent and treat rejection. However, CS are associated with increased risk of infection, obesity, hypertension, hyperlipidemia, diabetes, and bone necrosis. They have also been implicated in accelerating Hepatitis $\mathrm{C}(\mathrm{HCV})$ recurrence postliver transplantation (OLT). This study assesses the safety and efficacy of completely CSfree immunosuppressive regimen in adult OLT.

Methods. A 2-year, prospective, randomized study of CS or no-CS immunosuppressive regimen with basiliximab, tacrolimus and enteric-coated mycophenolate sodium (EC-MPS) was performed in 39 patients $(\mathrm{CS}=20$, group $\mathrm{A}$; No-CS=19, group B). The CS cohort received intra-operative methylprednisolone 1 gram intravenously tapered and weaned off by 6 months. HCV patients had HCV PCR pre-OLT, 0.5, 1, 3, 6 months post-OLT. Protocol liver biopsies were performed at OLT, 2 weeks, and 6 months post-OLT or when clinically indicated.

Results. CS-responsive acute rejection occurred in one patient in each group. Patient survival rates at 1 year (100\% vs. 94\%), 3 and 5 years (85\% vs. 63\%) post-OLT were similar between group A and B, respectively. Death-censored graft survival rates at 1 year (100\% vs. 100\%), 
3 and 5 years ( $85 \%$ vs. $79 \%)$ were also similar between group A and B, respectively. The risk of new onset DM, hypertension, hypercholesterolemia, and weight gain was similar between 2 groups.

Conclusion. Complete CS-avoidance with basiliximab, calcineurin inhibitor (CNI), and ECMPS is safe and effective as CS-containing immunosuppressive regimen in adult OLT.

\section{INTRODUCTION}

Corticosteroids (CS) have always been an integral part of standard post-transplant immunosuppression for prevention and treatment of rejection. First introduced in the early 1950s, CS have been used widely since the first successful orthotopic liver transplantation (OLT) in 1967 (1). CS exert potent immunosuppressive and anti-inflammatory effects through their action on leukocytes by stimulation or inhibition of gene transcription, altering gene expression responsible for mounting immune and inflammatory responses. However, CS use has been shown to cause long-term adverse effects, which include diabetes, increased susceptibility to infection, obesity, hypertension, hyperlipidemia, osteopenia, cataracts and growth retardation in children. CS have also been implicated in accelerating Hepatitis C (HCV) recurrence post-OLT (2-3). Consequently, several clinical trials which adopted early CS reduction and cessation after OLT were conducted and showed no increase in safety risks (4-6). In recent years, a small but increasing proportion of transplant centers, including our group, have demonstrated that adult and pediatric OLT may be successfully performed with CS minimization (7-11).

Prior to this study the standard immunosuppressive protocol at Thomas Jefferson University Hospital (TJUH) for OLT recipients included basiliximab induction and CS 
intraoperatively, followed by calcineurin inhibitor (CNI), mycophenolate mofetil (MMF), and CS maintenance therapy.

\section{RESULTS}

Between February 2006 and November 2007, forty adult OLT recipients were enrolled in the study and 20 recipients were randomized to each group. One recipient in the CS-free group required a re-transplantation for hepatic artery thrombosis on post-OLT day 16. Since he expired within 10 days after re-transplantation, follow up data was short and untenable and therefore, he was excluded from the study analysis.

The mean overall follow-up was 47.3 months as of July 2011. Donor characteristics were comparable between the two groups (Table 1). Other than a significantly higher mean recipient age and longer mean hospital stay in group B compared to group A, recipient demographics and peri-operative data were similar between the two groups. There were 3 outliers in group B with mean hospital stay of 67.7 (range: 43-89) days. One had a protracted surgical ICU stay due to prolonged ventilator dependence, atrial fibrillation, and poor mental status. Another patient had ventilator-dependent adult respiratory distress syndrome, hepatopulmonary syndrome, acute renal failure, sepsis, and massive colonic bleeding. The third patient had a MELD score of 35 at OLT with hepato-renal syndrome (Table 1).

\section{Primary end points}

There was no significant difference in patient and death-censored graft survival rates between the 2 groups. The 1-, 3-, and 5-year patient survival rates in group A and group B, respectively were: $100 \%$ vs. $94 \%, 85 \%$ vs. $63 \%$, and $85 \%$ vs. $63 \%$ (Figure1). The 1-, 3-, and 5-year graft survival rates in group A and B, respectively were: $100 \%$ vs. $100 \%, 85 \%$ vs. $79 \%$, and $85 \%$ vs. $79 \%$ (Figure 2). There were 10 deaths, 3 in group A and 7 in group B. The causes of death in group A were: cerebrovascular accident $(\mathrm{n}=1)$, and liver failure secondary 
to severe progressive $\mathrm{HCV}$ recurrence $(\mathrm{n}=2)$. In group $\mathrm{B}$, the causes of death were: cerebrovascular accident $(n=1)$, necrotizing pancreatitis post-endoscopic retrograde cholangiopancreatography $(n=1)$, self-inflicted gun shot wound to the head $(n=1)$, and liver failure secondary to severe progressive HCV recurrence $(n=4)$. The mean time to death from OLT was 21.5 months in group A and 24.7 months in group B ( $\mathrm{p}=\mathrm{ns})$. CS-responsive biopsyproven acute rejection occurred once in 1 patient (5\%) in each group.

Secondary end points.

The mean peak aspartate aminotransferase (AST), alanine aminotransferase (ALT), total bilirubin and international normalized ratio (INR) levels and the mean days to peak post-OLT were similar between the 2 groups. The time to transaminase peak occurred on POD 2 and POD 1 in groups A and B, respectively, while the mean time to INR peak was $<1$ day for both groups. Furthermore, there was no incidence of primary non-function in this cohort (Table 2).

The mean weight decreased in group A and group B from baseline to one month postOLT. However, from 1-month to 1-year post-OLT, mean weight increased steadily in group A but decreased in group B, although the difference was not significant. Mean cholesterol levels were similar in both groups from baseline to 12 months post-OLT. The mean arterial pressure (MAP) in group A increased from baseline to 3 months before they started to decrease by 6 months post-OLT. Likewise, MAP in group B increased from baseline to 1 month before they trended downwards by the $3^{\text {rd }}$ month post-OLT. Mean FBS levels at baseline, 1, 3, and 12 months post-OLT were similar, except at 6 months post-OLT when FBS levels were significantly higher $(\mathrm{p}=0.02)$ in group A compared to group B. Eight recipients in each group developed NODM with mean FBS levels (mg/dl) of 148 and 152 in group A and B, respectively (Table 2). 
A total of 12 patients in each group developed bacterial infection. No single case of CMV infection/disease was observed in the cohort. Furthermore, there was no recurrent HCC or new malignancy noted on last follow-up.

There were more HCV recipients in group B (74\%) than in group A (55\%). We also observed an earlier peak ( 1 vs. 3 months post-OLT) and higher HCV PCR levels (16 million vs. 11.9 million, $\mathrm{p}=\mathrm{ns}$ ) in group A than in group B. However, the incidence and severity of HCV recurrence were similar in both groups based on liver biopsy results. Anti-viral treatment outcomes are listed in Table 3.

Mean tacrolimus trough levels $(\mathrm{ng} / \mathrm{ml})$ were similar at $1,3,6$, and 12 month postOLT in group A $(11.3,9,7.8,7.5)$ and $\mathrm{B}(8.1,7.8,9.4,6)$, respectively. The mean duration on CS was 174 days in Group A. EC-MPS was given for a mean duration of 2.9 months postOLT in both groups. EC-MPS dose reduction was carried out for gastro-intestinal symptoms (diarrhea, vomiting) in 4 patients in each group; and for neutropenia in 3 and 6 recipients in group A and B, respectively. EC-MPS was discontinued for GI symptoms in 1 recipient in each group; and for neutropenia in 2 and 1 recipient in group A and B, respectively.

\section{DISCUSSION}

Corticosteroids have been used widely for decades as part of immunosuppressive therapy in OLT despite their various associated long term adverse effects. In an attempt to reduce or avoid CS adverse effects, several transplant centers have successfully tried CS minimization or early CS withdrawal protocols post-OLT (4-11) and have reported similar graft failure rates with reduction and better control of hypertension, diabetes, obesity, and hypercholesterolemia, which are major risk factors known to accelerate atherosclerotic heart disease $(10,12)$. In recent years, a few CS-free immunosuppressive protocols have been proposed post-OLT (7-8, 13-19). Some CS-free protocols included the use of intra-operative 
dose of CS followed by post-OLT CS-free maintenance therapy (8, 20-24). Although CSfree protocols were reported to be safe compared to historical controls, these regimens have not been widely adopted by many transplant programs. Our aim was to evaluate the safety and efficacy of complete CS-avoidance compared to standard CS-containing immunosuppressive regimen consisting of basiliximab induction and tacrolimus, EC-MPS maintenance immunosuppression in adult OLT recipients.

The protective effect of CS treatment in ameliorating ischemia-reperfusion (I-R) injury and reducing acute rejection in deceased-donor OLT has been verified in a prospective randomized study (25). However, this approach was questioned by animal studies which showed that CS given at the time of transplantation could enhance I-R injury by increasing DNA fragmentation, and apoptosis after reperfusion (26), and by inhibiting TNF and IL-6 expression, which impairs cell-cycle progression, and hepatocyte regeneration (27). Our trial showed no difference in the incidence of I-R injury between CS-containing and CS-free groups, supporting Pirenne's (10) findings that intra-operative high dose CS bolus has no protective effect on I-R injury.

A recent meta-analysis of 19 randomized trials which compared CS-treated to CSfree immunosuppression reported that the CS-free groups demonstrated a trend toward lower hypertension and statistically significant reduction in cholesterol levels and CMV infection (28). Contrary to these results our prospective randomized trial did not show any difference between the two groups in the incidence of hypertension, cholesterol levels or CMV infection. Although not significant, our results showed a tendency toward increased weight gain in the CS-treated group, which is an anticipated consequence of long term CS use. This disparity may be explained by the heterogeneity of immunosuppressive protocols used by the individual centers, the short period of follow up and the small sample size of the various trials in the meta- analysis groups. The meta-analysis also suggested that the risk of NODM 
would be markedly lower in the CS-free arm if CS were replaced with another immunosuppressive agent such as an anti-IL2 antibody, polyclonal anti-T-cell antibody or MMF, which was not demonstrated in our study. Our study also showed that FBS levels were similar between groups except at 6 months post-OLT when they were higher in the CStreated group. The reason for this unexpectedly higher glucose level at 6 months is unclear considering that most recipients in the CS-treated group were no longer on CS by 6 months post-OLT.

Our study showed an overall low ACR rate of 5\% and similar 1-, 3-, and 5-year patient and graft survival rates between CS-containing and CS-free groups. These may be attributed to the use of anti-IL2 induction in combination with dual CNI/MPA maintenance immunotherapy.

$\mathrm{HCV}$ recurrence post-OLT is almost a universal phenomenon. The incidence of histological HCV recurrence ranges from $14 \%$ to $72 \%$ (29-30). Furthermore, a severe cholestatic type of recurrent $\mathrm{HCV}$, characterized by rapid progression to graft failure requiring re-transplantation within 2 years, has been reported in about $10 \%$ of $\mathrm{HCV}$ recipients (31-32). Contrary to these findings, our study showed higher overall incidence of histologic HCV recurrence (81\%), and severe cholestatic HCV recurrence (28\%). Furthermore, although the mean PCR levels peaked higher and earlier in the steroid group compared to steroid-free group, there was no difference in the incidence and severity of HCV recurrence, treatment outcomes, and graft loss rates between the two groups. These findings are consistent with the suggestions of Eghtesad et al. (33) that viremia or avoidance of specific immunosuppressive drug such as CS is not critical in promoting accelerated $\mathrm{HCV}$ recurrence post-OLT. Instead, they suggested that timing and continuity of immunosuppressive drugs post-OLT, which regulate the overall balance between virus 
distribution and immune responsiveness, are more important factors affecting treatment outcomes in HCV recipients.

Mycophenolate mofetil has been one of the newer therapies in OLT in the last decade. However, MMF has been associated with diarrhea, nausea, vomiting, abdominal pain, etc. EC-MPS was developed in an effort to lessen these side effects. Renal transplant studies have shown the use of EC-MPS to be as effective and as safe as MMF (34- 35). However, studies on de novo use of EC-MPS in OLT recipients have been limited to conversion from MMF to EC-MPS (36-38). One study analyzed and showed that EC-MPS has similar efficacy to MMF as a primary immunosuppressant or as an MMF replacement in OLT recipients (39). Our data showed that EC-MPS was well tolerated with similar incidence of side effects between CS-treated and CS-free groups, most of which resolved with dose reduction. Neutropenia was observed less frequently in the CS-treated group, which could explain why over $90 \%$ in this group tolerated optimal dosing of EC-MPS. We suggest that the low incidence of neutropenia in the CS-treated group may be related to the effect of CS in increasing white blood cell count.

In this study, no recipient with autoimmune-mediated liver disorder, i.e., primary biliary cirrhosis, primary sclerosing cholangitis, and autoimmune hepatitis, was randomized in the CS-free group. It is well recognized that this subgroup of recipients may develop disease recurrence in the liver allograft and reported to have a higher incidence of acute and chronic ACR and perhaps may benefit from continuous, long term CS immunoprophylaxis (40-41). Consequently, extra caution should be exercised when selecting recipients who can safely be included in a completely CS-free regimen.

In conclusion, our analysis suggests that complete CS avoidance in adult OLT using basiliximab induction with CNI and EC-MPS maintenance is as safe and as effective as 
standard CS-containing immunosuppression when evaluating for graft function, acute rejection, and patient and graft survival. Contrary to other studies, our results did not show any significant difference between CS-treated and CS-free groups in the incidence of hypertension, hypercholesterolemia, NODM, and weight gain. Furthermore, our data did not validate the common belief that CS-free immunosuppression has a beneficial effect in reducing the incidence, severity or degree of progression of HCV recurrence post-OLT.

\section{MATERIALS AND METHODS}

Institutional Review Board approval from TJUH was granted and informed consent was obtained from all subjects enrolled in this study, conforming to the ethical guidelines of the Declaration of Helsinki. Between February 2006 and November 2007, forty adult recipients of deceased donor primary OLT at TJUH were enrolled into this prospective, controlled, randomized, non-blinded, pilot trial. The primary objective was to assess the efficacy and safety of a completely CS-free immunosuppressive regimen in OLT, by comparing graft and patient survival rates and incidence and treatment of acute cellular rejection (ACR), between recipients treated with and without CS. The secondary objective was to compare the incidence of CS-related metabolic complications and HCV recurrence between recipients treated with and without CS. Common side effects associated with enteric-coated mycophenolate sodium (EC-MPS) use, i.e., neutropenia and gastro-intestinal symptoms, were also evaluated.

Inclusion criteria: adult recipients of primary cadaveric OLT between 18- 72 years

old, liver graft cold ischemia time of $<20$ hours, and women of childbearing potential with negative pregnancy test. The exclusion criteria included: multiple organ transplant 
recipients, women of childbearing potential not using the prescribed contraceptive methods, and use of any other investigational agent within 30 days prior to enrollment.

All recipients received basiliximab $20 \mathrm{mg}$ IV intra-operatively and on post-operative day (POD) 4. Maintenance immunosuppression included tacrolimus and EC-MPS. Tacrolimus was started at $0.10 \mathrm{mg} / \mathrm{kg} /$ day by mouth (PO) or nasogastric tube (NGT) in 2 divided doses, within 48 hrs after reperfusion. The dose was adjusted to achieve target trough level 8-12 ng/ml in first month post-OLT, and 5-8 ng/ml, thereafter. All recipients received MMF $1 \mathrm{~g}$ every 12 hours via NGT until they could take oral medications, after which they were switched to EC-MPS $720 \mathrm{mg}$ PO twice daily for three months post-OLT.

Recipients were randomized into either treatment arms: Control arm (group A) standard immunosuppression with CS; and CS-free arm (group B) - standard immunosuppression without CS. Group A received methylprednisolone $1 \mathrm{~g}$ IV intraoperatively followed by a taper schedule as follows: methylprednisolone $50 \mathrm{mg}$ IV every 6 hours on day 1; $40 \mathrm{mg}$ IV every 6 hours on day 2; $30 \mathrm{mg}$ IV every 6 hours on day 3; $20 \mathrm{mg}$ IV every 6 hours on day 4; $20 \mathrm{mg}$ IV every 12 hours on days 5; and thereafter, prednisone 20 mg PO daily which was tapered off by 6 months post-OLT. Group A and B recipients were on maintenance CNI monotherapy by 6 months and 3 months post-OLT, respectively.

All recipients received cytomegalovirus (CMV) prophylaxis with IV gancyclovir or valgancyclovir $450 \mathrm{mg}$ PO daily for at least 3 months. They also received prophylactic doses of trimethoprim sulfa 3 times weekly and nystatin swish and swallow 3 times daily.

Liver biopsies were performed according to protocol intra-operatively, between days 7 and 21 post-OLT and at 3-6 months post-OLT, and when clinically indicated. For HCV (+) 
recipients, quantitative HCV RNA PCR serum levels were performed at baseline, 0.5, 1, 3, and 6 months post-OLT.

Biopsy-proven ACR using the Banff Classification (42) was treated in both groups with methylprednisolone $1 \mathrm{~g}$ IV followed by a 5-day CS taper as described above. For recipients in group B who received CS for ACR, prednisone was tapered off by the third month after CS initiation. The protocol also required a repeat biopsy if there was no improvement in the liver function test at the end of CS taper.

A diagnosis of $\mathrm{HCV}$ recurrence was made based on liver biopsy findings and serum HCV RNA titers. Recipients with HCV recurrence were treated according to TJUH protocol as described below. Abnormal liver function tests were evaluated by hepatic ultrasound, and percutaneous liver biopsy. The TJUH protocol follows the modified Scheuer scoring system (43-44) to evaluate the need for anti-viral treatment in chronic hepatitis post-OLT. If the liver biopsy shows total score of $>4$ for necro-inflammatory activity (greater than mild portal and lobular inflammation) or $>$ stage 1 (enlarged and fibrotic portal tracts), treatment with PegInterferon $180 \mu \mathrm{g}$ subcutaneously weekly for 2 weeks would be started. If the recipient tolerates peg-interferon without hematologic or neuro-psychiatric complications, ribavirin is added to Peg-interferon for a total duration of 48 weeks.

Weight, total cholesterol, fasting blood sugar (FBS), and mean arterial pressure (MAP) levels were measured and recorded at baseline, 1, 3, 6 and 12 months post-OLT. New onset diabetes mellitus (NODM) was defined as FBS $\geq 126 \mathrm{mg} / \mathrm{dl}(7 \mathrm{mmol} / \mathrm{l})$, with fasting defined as no caloric intake for at least 8 hours.

STATISTICAL ANALYSIS: Statistical analysis was done to demonstrate equivalence or non-inferiority of the CS-free immunosuppressive regimen compared to the 
standard protocol with CS for both primary and secondary end points. All continuous

variables were summarized with mean and standard error and all categorical variables

summarized as percentages. Statistical significance for each test was reported at $p \leq 0.05$.

For continuous values, each group was compared using a two-tailed, independent Student's t-

test assuming equal or unequal variance based on the results of an F-test. Each categorical

variable was compared using a two-tailed Fisher's exact test. Survival analysis was done

with Kaplan-Meier and significance was determined using a log-rank test. Analysis was

performed using XLSTAT 2008 (Addinsoft, 2008) for Microsoft Excel.

\section{REFERENCES}

1. Starzl TE, Marchioro TL, Porter KA, et al. Homotransplantation of the liver. Transplantation. 1967; 5 (Supplement):790-803.

2. Gane E, Naoumov NV, Qian KP, et al. A longitudinal analysis of hepatitis C virus replication following liver transplantation. Gastroenterology. 1996; 110: 167-177.

3. Fukumoto $\mathrm{T}$, Berg $\mathrm{T}, \mathrm{Ku} \mathrm{Y}$, et al. Viral hemodynamics of Hepatitis $\mathrm{C}$ early after orthotopic liver transplantation: evidence for rapid turnover of serum virions. Hepatology. 1996; 24 (6): 1351-1354.

4. Greig P, Lilly L, Scudamore C, et al. Early steroid withdrawal after liver transplantation: the Canadian tacrolimus versus microemulsion cyclosporin A trial: 1year follow-up. Liver Transpl. 2003; 9(6):587-95.

5. Belli LS, De Carlis L, Rondinara G, et al. Early cyclosporine monotherapy in liver transplantation: a 5-year follow-up of a prospective, randomized trial. Hepatology. 1998; 27(6):1524-29.

6. Stegall MD, Wachs ME, Everson G, et al. Prednisone withdrawal 14 days after liver transplantation with mycophenolate: a prospective trial of cyclosporine and tacrolimus. Transplantation. 1997; 64(12): 1755-1760.

7. Eason, JD, Loss GE, Blazek J, et al. Steroid Free liver transplantation using RATG: results of a prospective randomized trial. Liver Transpl. 2001; 7(8): 693-697.

8. Tisone G, Angelico M, Palmieri G, et al. A Pilot Study on the safety and effectiveness of immunosuppression without prednisone after liver transplantation. Transplantation 1999; 67 (10): 1308-1313.

9. Reding R, Gras J, Sokal E, et al. Steroid free liver transplantation in children. Lancet. 2003; 362:2068-2070.

10. Pirenne J, Aerts R, Koshiba T, et al. Steroid-free immunosuppression during and after liver transplantation- A 3-yr follow-up report. Clin Transplant. 2003; 17:177-82

11. Marino IR, Doria C, Scott V, et al. Efficacy and safety of basiliximab with a tacrolimus based regimen in liver transplant recipients. Transplantation 2004; 78:886. 
12. Everson GT, Trouillot T, Wachs M, et al. Steroid withdrawal in liver transplantation is safe and beneficial. Liver Transplant Surg. 1999; 5:S4-8.

13. Fasola CG, Klintmalm GB. Hepatitis $C$ recurrence after liver transplantation: in search of the optimal immunosuppression to improve outcome. Curr Opin Organ Transplant. 2006; 11:637-642.

14. Belli LS, Alberti AB, Rondinara GF, et al. Early ribavirin treatment and avoidance of corticosteroids in hepatitis $\mathrm{C}$ virus (HCV)-positive liver transplant recipients: interim report of a prospective randomized trial. Transplant Proc. 2001; 33:1353-1354.

15. Kato T, Yoshida H, Sadfar K, et al. Steroid-free induction and preemptive antiviral therapy for liver transplant recipients with hepatitis C: a preliminary report from a prospective randomized study. Transplant Proc. 2005;37:1217-1219.

16. Llado L, Xiol X, Figueras J, et al. Immunosuppression without steroids in liver transplantation is safe and reduces infection and metabolic complications: results from a prospective multicenter randomized study. J Hepatol. 2006; 44: 710-716.

17. Pelletier SJ, Vanderwall K, Debroy MA, et al. Preliminary analysis of early outcomes of a prospective, randomized trial of complete steroid avoidance in liver transplantation. Transplant Proc. 2005; 37: 1214-1216.

18. Reggiani P, Arru M, Regazzi M, et al. A "steroid-free" tacrolimus and low-dose mycophenolate mofetil primary immunosuppression does not prevent early acute rejection after liver transplantation. Transplant Proc. 2005;37:1697-1699

19. Filipponi F, Callea F, Salizzoni M, et al. Double-blind comparison of hepatitis C histological recurrence rate in $\mathrm{HCV}$ - liver transplant recipients given Basiliximabsteroids or Basiliximab-placebo, in addition to cyclosporine and azathioprine. Transplantation. 2004; 78:1488-1495.

20. Ringe B, Braun F, Schütz E, et al. A novel management strategy of steroid-free immunosuppression after liver transplantation: efficacy and safety of tacrolimus and mycophenolate mofetil. Transplantation. 2001; 71: 508-515.

21. Margarit C, Bilbao I, Castells L, et al. A prospective randomized trial comparing tacrolimus and steroids with tacrolimus monotherapy in liver transplantation: the impact on recurrence of hepatitis C. Transpl Int. 2005; 18: 1336-1345.

22. Boillot O, Mayer DA, Boudjema K, et al. Corticosteroid-free immunosuppression with tacrolimus following induction with daclizumab: a large randomized clinical study. Liver Transpl. 2005; 11: 61-67.

23. Langrehr JM, Neumann UP, Lang M, et al. First results from a prospective randomized trial comparing steroid-free induction therapy with tacrolimus and MMF versus tacrolimus and steroids in patients after liver transplantation for HCV. Transplant Proc. 2002; 34 (5):1565-1566.

24. Lerut JP. Avoiding steroids in solid organ transplantation. Transpl Int. 2003; 16 (4): 213-224.

25. Kotsch K, Ulrich F, Reutzel-Selke A, et al. Methylprednisolone therapy in deceased donor reduces inflammation in the donor liver and improves outcome after liver transplantation. Ann Surg. 2008; 248 (6): 1042-1050.

26. Sileri P, Schena S, Fukuda J, et al. Corticosteroids enhance hepatic injury following ischemia-reperfusion. Transplant Proc. 2001; 33 (7-8): 3712.

27. Debonera F, Krasinkas AM, Gelman AE, et al. Dexamethasone inhibits early regenerative response of rat liver after cold preservation and transplantation. Hepatology. 2003; 38 (6): 1563-1572.

28. Segev DL, Sozio SM, Shin EJ, et al. Steroid avoidance in liver transplantation: metaanalysis and meta-regression of randomized trials. Liver Transpl. 2008; 14:512-525. 
29. Singh N, Gayowski T, Wannstedt CF, et al. Interferon alpha therapy for hepatitis C virus recurrence after liver transplantation: long term response with maintenance therapy. Clin Transplant. 1996; 10 (4): 348-351.

30. Gayowski T, Singh N, Marino IR, et al. Hepatitis C genotypes in liver transplant recipients: impact on post-transplant recurrence, infections, response to interferon- $\alpha$ therapy and outcome. Transplantation. 1997; 64 (3):422-426.

31. Schluger LK, Sheiner PA, Thung SN, et al. Severe recurrent cholestatic hepatitis C following orthotopic liver transplantation. Hepatology. 1996; 23 (5): 971-976.

32. Dickson RC, Caldwell SH, Ishitani MB, et al. Clinical and histological patterns of early graft failure due to recurrent hepatitis $\mathrm{C}$ in four patients after liver transplantation. Transplantation. 1996; 61 (5):701-705.

33. Eghtesad B, Fung JJ, Demetris AJ, et al. Immunosuppression for liver transplantation in HCV-infected patients: mechanism-based principles. Liver Transpl. 2005; 11(11):1343-52.

34. Sollinger HW. Mycophenolate mofetil for the prevention of acute rejection in primary cadaveric renal allograft recipients. U.S. Renal Transplant Mycophenolate Mofetil Study Group. Transplantation. 1995; 60(3):225-32.

35. The Tricontinental Mycophenolate Mofetil Renal Transplantation Study Group. A blinded, randomized clinical trial of mycophenolate mofetil for the prevention of acute rejection in cadaveric renal transplantation. Transplantation. 1996; 61(7):102937.

36. Miras M, Carballo F, Egea J, et al. Clinical evolution in the first 3 months of patients after liver transplantation in maintenance phase converted from mycophenolate mofetil to mycophenolate sodium due to gastrointestinal complications. Transplant Proc. 2007; 39(7):2314-7.

37. Dumortier J, Gagnieu MC, Salandre J, et al. Conversion from mycophenolate mofetil to enteric-coated mycophenolate sodium in liver transplant patients presenting gastrointestinal disorders: a pilot study. Liver Transpl. 2006; 12 (9):1342-6.

38. Robaeys G, Cassiman D, Verslype C, et al. Successful conversion from mycophenolate mofetil to enteric-coated mycophenolate sodium (myfortic) in liver transplant patients with gastrointestinal side effects. Transplant Proc. 2009; 41(2):610-613.

39. Cantisani GP, Zanotelli ML, Gleisner AL, et al. Enteric-coated mycophenolate sodium experience in liver transplant patients. Transplantation Proc. 2006; 38(3): 932-933.

40. Neuberger J. Recurrence of primary biliary cirrhosis, primary sclerosing cholangitis, and auto-immune hepatitis. Liver Transpl Surg 1995; 1: 109-115.

41. Hayashi M, Keefe EB, Krams SM, et al. Allograft rejection after liver transplantation for autoimmune liver diseases. Liver Transpl Surg. 1998; 4():208-214.

42. Demetris AJ, Batts KP, Dhillon AP, et al. Banff schema for grading liver allograft rejection: an international consensus document. Hepatology. 1997; 25:658.

43. Scheuer PJ. Classification of chronic viral hepatitis: a need for reassessment. J Hepatol.1991; 13: 372.

44. Brunt EM. Grading and staffing the histopathological lesions of chronic hepatitis: the Knodell histology activity index and beyond. Hepatology. 2000; 31:241. 


\section{ACKNOWLEDGEMENT}

This study was supported by a research grant from the Novartis Pharmaceuticals Corporation.

The authors would like to acknowledge the following professionals for their valued contribution in data collection and editing the manuscript:

1. Thomas E. Starzl, MD, PhD, University of Pittsburgh, 3459 Fifth Avenue, Pittsburgh, PA 15213

2. Silvia Vaccino, MBA, Former Research Coordinator, Division of Transplantation, Department of Surgery, Thomas Jefferson University, Philadelphia, PA.

3. Vincent Armenti, MD, PhD, Division of Transplantation, Department of Surgery, Thomas Jefferson University, Philadelphia, PA.

4. Mark Chaballa, PharmD, Department of Pharmacy, Thomas Jefferson University Hospital, Philadelphia, PA. 
TABLES

Table 1. Recipient \& Donor demographics and baseline (pre-OLT) characteristics

\begin{tabular}{|c|c|c|c|}
\hline Donor Variables & Group A & Group B & p-value \\
\hline Donor Age (years), mean \pm SD & $48.1 \pm 4.3$ & $45.5 \pm 3.5$ & ns \\
\hline Donor Sex $(\mathrm{M} / \mathrm{F}), \mathrm{n}$ & $12 / 8$ & $12 / 7$ & ns \\
\hline Donor Race, $\mathrm{n}$ & $\begin{array}{l}\text { Caucasian: } 13 \\
\text { Non-Caucasian: } 7\end{array}$ & $\begin{array}{l}\text { Caucasian: } 13 \\
\text { Non-Caucasian: } 6\end{array}$ & ns \\
\hline Donor $\mathrm{HCV}+, \mathrm{n}$ & 1 & 3 & ns \\
\hline \multicolumn{4}{|l|}{ Recipient Variables } \\
\hline Age, (years), mean \pm SE & $50.40 \pm 2.6$ & $56.2 \pm 1.1$ & 0.05 \\
\hline $\operatorname{Sex}(M / F), n$ & $15 / 5$ & $14 / 5$ & ns \\
\hline Race, $n$ & $\begin{array}{l}\text { Caucasian: } 16 \\
\text { Non-Caucasian: } 4\end{array}$ & $\begin{array}{l}\text { Caucasian: } 16 \\
\text { Non-Caucasian: } 3\end{array}$ & ns \\
\hline * Primary Diagnosis: $\mathrm{n}$ & $\begin{array}{l}\text { Cryptogenic: } 2 \\
\text { HCV: } 11 \\
\text { HBV: } 2 \\
\text { PSC: } 2 \\
\text { HCC: } 10 \\
\text { LC: } 3 \\
\text { NASH: } 1\end{array}$ & $\begin{array}{l}\text { Cryptogenic: } 1 \\
\text { HCV: } 14 \\
\text { HBV: } 2 \\
\text { Budd-Chiari: } 1 \\
\text { HCC: } 11 \\
\text { LC: } 6\end{array}$ & ns \\
\hline MELD Score, mean \pm SD & $23.2 \pm 1.5$ & $24.4 \pm 2$ & ns \\
\hline $\mathrm{DM}, \mathrm{n}$ & 5 & 4 & ns \\
\hline Hypertension, $\mathrm{n}$ & 7 & 7 & ns \\
\hline Weight (lbs), mean \pm SD & $173.8 \pm 9.6$ & $171.5 \pm 7.7$ & ns \\
\hline \multicolumn{4}{|l|}{$\begin{array}{l}\text { Recipient Peri-operative Data } \\
(\text { mean } \pm \text { SE) }\end{array}$} \\
\hline Cold ischemia time (h:min) & $7: 25 \pm 0: 23$ & $7: 52 \pm 0: 38$ & ns \\
\hline $\begin{array}{l}\text { Intra-operative red blood cell } \\
\text { transfusion (units) }\end{array}$ & $7.9 \pm 1.6$ & $9.5 \pm 1.5$ & ns \\
\hline
\end{tabular}




\begin{tabular}{|l|l|l|c|}
\hline Total OR time (h:mm) & $9: 10 \pm 1: 19$ & $8: 44 \pm 1: 17$ & $\mathrm{~ns}$ \\
\hline Intensive care unit (days) & $3.6 \pm 0.39$ & $5.8 \pm 1.27$ & $\mathrm{~ns}$ \\
\hline Hospital length of stay (days) & $16.7 \pm 1.7$ & $28.6 \pm 5.1$ & 0.04 \\
\hline & & & \\
\hline & & & \\
\hline
\end{tabular}

* Some patients presented multiple diagnoses. $\mathrm{HCV}$, hepatitis $\mathrm{C}$ virus; PSC, primary sclerosing cholangitis; HCC, hepatocellular carcinoma; HBV, hepatitis B virus; NASH, nonalcoholic steatohepatitis; LC, Laennec's cirrhosis

Table 2. Recipient Metabolic Panels

\begin{tabular}{|l|l|l|l|}
\hline Clinical Variables & Group A & Group B & p-value \\
\hline Liver function tests & & & \\
\hline Peak AST (IU/L) & 2,357 & 1,503 & $\mathrm{~ns}$ \\
\hline Peak ALT (IU/L) & 1,151 & 813 & $\mathrm{~ns}$ \\
\hline Total Bilirubin (mg/dl) & 9.5 & 11.8 & $\mathrm{~ns}$ \\
\hline INR & 2.61 & 2.79 & $\mathrm{~ns}$ \\
\hline Mean weight (lbs) & & & \\
\hline Baseline & 174 & 167 & $\mathrm{~ns}$ \\
\hline 1-month post-OLT & 165 & 163 & $\mathrm{~ns}$ \\
\hline 3-months post-OLT & 168 & 157 & $\mathrm{~ns}$ \\
\hline 6-months post-OLT & 176 & 156 & $\mathrm{~ns}$ \\
\hline 12-months post-OLT & 181 & 157 & $\mathrm{~ns}$ \\
\hline Cholesterol (mg/dl) & & & \\
\hline Baseline & 94 & 91 & $\mathrm{~ns}$ \\
\hline 1-month post-OLT & 155 & 157 & $\mathrm{~ns}$ \\
\hline 3-months post-OLT & 151 & 143 & $\mathrm{~ns}$ \\
\hline 6-months post-OLT & 165 & 149 & $\mathrm{~ns}$ \\
\hline 12-months post-OLT & 146 & 160 & $\mathrm{~ns}$ \\
\hline Mean arterial pressure (MAP) & & & \\
\hline Baseline & 84 & 89 & $\mathrm{~ns}$ \\
\hline 1-month post-OLT & 93 & 96 & $\mathrm{~ns}$ \\
\hline 3-months post-OLT & 99 & 91 & $\mathrm{~ns}$ \\
\hline 6-months post-OLT & 98 & 94 & $\mathrm{~ns}$ \\
\hline 12-months post-OLT & 96 & 91 & $\mathrm{~ns}$ \\
\hline Fasting blood sugar (mg/dl) & & 148 & $\mathrm{~ns}$ \\
\hline Baseline & 148 & 106 & \\
\hline 1-month post-OLT & 111 & & \\
\hline 3-months post-OLT & 117 & \\
\hline
\end{tabular}


20

\begin{tabular}{|l|l|l|l|}
\hline 6-months post-OLT & 144 & 98 & 0.02 \\
\hline 12-months post-OLT & 147 & 112 & $\mathrm{~ns}$ \\
\hline
\end{tabular}

Table 3. Hepatitis Recurrence

\begin{tabular}{|c|c|c|c|}
\hline Clinical Variables & Group A & Group B & $\mathrm{p}$-value \\
\hline Total number of HCV recipients & $11 / 20(55 \%)$ & $14 / 19(74 \%)$ & ns \\
\hline Mean HCV RNA PCR & & & \\
\hline Pre-OLT & $0.48 \mathrm{M}$ & $0.45 \mathrm{M}$ & ns \\
\hline 2 weeks post-OLT & $5.8 \mathrm{M}$ & $0.83 \mathrm{M}$ & ns \\
\hline 1 month post-OLT & $15.9 \mathrm{M}$ & $3.7 \mathrm{M}$ & ns \\
\hline 3 months post-OLT & $12.3 \mathrm{M}$ & $11.9 \mathrm{M}$ & ns \\
\hline 6 months post-OLT & $11.1 \mathrm{M}$ & $5.5 \mathrm{M}$ & ns \\
\hline Treatment for HCV recurrence & $7 / 11(64 \%)$ & $9 / 14(64 \%)$ & ns \\
\hline No Treatment for HCV recurrence & $4 / 11(36 \%)$ & $5 / 14(36 \%)$ & ns \\
\hline Mean duration of treatment (wks) & $38.5(4-52)$ & $19.3(2-46)$ & 0.048 \\
\hline Sustained viral response (SVR) & $2 / 11(18 \%)$ & $2 / 14(14 \%)$ & ns \\
\hline Non-responder to treatment & $3 / 11(27 \%)$ & $3 / 14(21 \%)$ & ns \\
\hline $\mathrm{HCV}$ progression to cirrhosis & $3 / 11(27 \%)$ & $4 / 14(29 \%)$ & ns \\
\hline Mean OLT to death interval (months) & 25.9 & 25.4 & ns \\
\hline
\end{tabular}


